\title{
PAPAGAIO AMIGO - APLICATIVO VOCALIZADOR COM ATIVIDADES PARA TEA
}

\author{
Jairo Francesco da Silva, ULBRA, jairofrantiesco@gmail.com \\ Maria Adelina Raupp Sganzerla, ULBRA, maria.sganzerla@ulbra.br \\ Marlise Geller, ULBRA/PPGECIM, marlise.geller@ulbra.br
}

Resumo: Este artigo apresenta um recorte da monografia de conclusão de curso em Ciência da Computação, Papagaio Amigo, um aplicativo móvel vocalizador, facilitando o uso da Comunicação Alternativa e Aumentativa (CAA) tendo como base os princípios da Tecnologia Assistiva (TA), disponibilizando um conjunto de símbolos gráficos e pessoais, e incluindo duas atividades ao usuário, utilizando-se das técnicas da CAA, e faz uso do modelo de desenvolvimento híbrido para aplicações móveis, usando ferramentas como o Intel XDK para codificar programação Web e acessar recursos de hardware do dispositivo. Sua validação foi efetivada com um grupo de 31 pessoas composto por responsáveis, professores e profissionais da saúde com experiência em comunicação com TEA (Transtorno do Espectro do Autismo) e uma criança diagnosticada com o transtorno, afim de verificar suas potencialidades.

Palavras-Chaves: Tecnologia Assistiva; Comunicação Alternativa e Aumentativa; Autismo.

\section{PARROT FRIEND - VOCAL APPLICATION WITH ACTIVITIES FOR TEA}

Abstract: This article presents a clipping of the monograph of course completion in Computer Science, Friend Parrot, a vocalizer mobile app, facilitating the use of Augmentative and Alternative Communication (AAC) based on the principles of Assistive Technology (AT), making available a set of graphical and personal symbols, and including two user-friendly activities using CAA techniques, and making use of the hybrid development model for mobile applications, using tools such as Intel XDK to encode Web programming and access device's hardware. It's validation was carried out with a group of 31 people composed of accountables, teachers and health professionals with experience in communication with Autism Spectrum Disorder (ASD) and a child diagnosed with the disorder in order to verify their potentialities.

Keywords: Assistive Technology; Aumentative and Alternative Communication; Autism.

\section{INTRODUÇÃO}

Atualmente a inclusão, bem como a melhor qualidade de vida para crianças com autismo vêm sendo discutida e estudada visando a criação de novas tecnologias. A Tecnologia Assistiva (TA) é uma das formas que possibilita os usuários a terem acesso à comunicação.

Garcia e Galvão Filho (2012) apontam que grande parte do avanço nas pesquisas atuais sobre TA, deve-se não só ao atual crescimento tecnológico acelerado, despertando curiosidades na exploração de descobertas recentes, mas também ao mérito das políticas públicas atuais que permitem às pessoas com deficiência a inclusão na escola regular.

A partir desse contexto e dos estudos realizados no Laboratório de Estudos de Inclusão (LEI), constitui-se o projeto "Tecnologias Assistivas para a Educação Matemática no Ensino Fundamental" ", tendo entre suas ações a implementação do Papagaio Amigo, parte do Trabalho de Conclusão de Curso Ciências da Computação da Ulbra/Gravatá em parceria com o Programa de Pós-Graduação em Ensino de Ciências e Matemática e o LSD (Laboratório de Sistemas Digitais), por meio de intervenções pedagógicas integrantes da Tese de Doutorado

\footnotetext{
${ }^{1}$ Aprovado pelo Edital de Apoio a Projetos de Tecnologia Assistiva - CNPq/MCTIC/SECIS No 20/2016.
} 
"Deficiência visual e a educação matemática: estudos sobre a implementação de Tecnologia Assistiva"2.

Tal projeto faz uso da Tecnologia Assistiva para pessoas diagnosticadas com Transtorno do Espectro do Autismo, inseridas nos anos iniciais do Ensino Fundamental e acompanhadas de um interlocutor, visando contribuir no uso da comunicação com gravuras e no armazenamento das mesmas utilizando um dispositivo móvel contendo um banco de imagens, que podem ser tocadas pelo usuário emitindo a respectiva palavra ou frase significativa do elemento.

\section{TEA - TRANSTORNO DO ESPECTRO DO AUTISMO}

O Transtorno do Espectro do Autismo caracteriza-se por comportamentos diferentes dos padrões sociais e interativos, onde os interesses dessas pessoas costumam ser individualizados. De acordo com o DSM-5 - Manual Diagnóstico e Estatístico de Transtornos Mentais, da Associação Psiquiátrica Americana (2014, p.31) estes indivíduos apresentam "défícits persistentes na comunicação social e na interação social em múltiplos contextos; incluindo déficits na reciprocidade social, em comportamentos não verbais de comunicação usados para interação social e em habilidades para desenvolver, manter e compreender relacionamentos". O Transtorno do Espectro do Autismo, dentro do conjunto relacionado a transtornos do neurodesenvolvimento, envolve condições que se manifestam no período inicial do desenvolvimento do indivíduo, e apresenta também padrões de comportamento restritos e repetitivos.

A Organização Mundial da Saúde (OMS, 2008), na elaboração da CID-10 (Classificação Estatística Internacional de Doenças e Problemas Relacionados à Saúde), caracteriza o Autismo dentro de Transtornos Globais de Desenvolvimento (TGD) que "são alterações qualitativas que constituem uma característica global do funcionamento do sujeito, em todas as ocasiões". As TGD são classificadas de acordo com a presença de manifestações patológicas atípicas suficientes em três áreas psicopatológicas: Interações sociais recíprocas, comportamentos limitados, estereotipados ou repetitivos, e comunicação.

Para a Associação Psiquiátrica Americana (2014), no Transtorno do Espectro do Autismo "pode haver um acentuado comprometimento no uso de múltiplos comportamentos não verbais (contato visual direto, expressão facial, posturas e linguagem corporal) que regulam a interação social e a comunicação". Os autistas costumam não fazer contato visual solicitações diretas, ignorando-as. Contudo, esses indivíduos podem estabelecer um contato não verbal para satisfazer interesses próprios, como alcançar objetos, sem qualquer preocupação social envolvida nas relações interpessoais. Eles também podem apresentar expressões faciais que não correspondem com o momento, podendo rir ou chorar sem um motivo aparente e fora de contexto com outras pessoas do ambiente. A dificuldade no relacionamento também impede a interação social em jogos e na formação de amizades, mostrando preferência por atividades solitárias.

Silva, Gaiato e Reveles (2012) analisam que:

A principal área prejudicada e a mais evidente é a da habilidade social. A dificuldade de interpretar os sinais sociais e as intenções dos outros impede que as pessoas com autismo percebam corretamente algumas situações do ambiente em que vivem. A segunda área comprometida é a comunicação verbal e não verbal. A terceira é a das inadequações comportamentais.

Conforme Nunes (2013), a "presença de déficit no desenvolvimento da linguagem e das habilidades comunicativas é evidente nos autistas desde os primeiros meses de vida", podendo

\footnotetext{
${ }^{2}$ Aprovada pelo Comitê de Ética sob protocolo número CAAE: 66101616.5.0000.5349.
} 
apresentar dificuldades em estabelecer uma comunicação funcional, assim como em responder a um chamado com o próprio nome. Outro aspecto especialmente interessante relatado por Passerino, Avila e Bez (2010, p.3) "é o que se refere às histórias ou narrativas, nesse âmbito, sujeitos com autismo também apresentam grandes dificuldades em contar histórias e em reter as características essenciais quando uma estória é contada para eles", muitas vezes pelo fato das representações serem muito diferente do seu dia a dia.

Seguindo essa premissa a comunicação alternativa pode auxiliar nesse contexto, sendo ela parte do conjunto de Tecnologia Assistiva (TA) que segundo Bersch (2008) é definida como "todo o arsenal de recursos e serviços que contribuem para proporcionar ou ampliar habilidades funcionais de pessoas com deficiência, promovendo vida independente e inclusão". Desta forma, ela ampara as limitações físicas ou mentais, proporcionando uma tentativa de equiparálas com os acessos de uma pessoa sem deficiência, promovendo ações individuais independentes e inclusão social, resultando a melhora na qualidade de vida do usuário.

Desta forma, a CAA faz parte de TA com o objetivo de auxiliar a limitação na comunicação usando recursos e serviços que sirvam de "porta voz" no contato com outras pessoas. Pelosi $(2009$, p.2) relata que é constituída por "um grupo integrado de componentes que inclui símbolos, recursos e técnicas adaptadas, que auxiliam as pessoas com disfunção ocupacional a se comunicarem e a participarem de suas atividades diárias".

Como exemplos de recursos para CAA podemos citar os símbolos não assistidos, onde a comunicação parte de gestos e símbolos do próprio corpo do indivíduo, e os assistidos, que incluem todo o objeto, seja real, miniatura, foto, gravura, palavras ou frases que representem objetos, pessoas, sentimentos ou ações desejadas pelo comunicador, dificultando a expressão dessas necessidades com o próprio corpo (NUNES, 2013). Esses materiais são utilizados por meio de pranchas de comunicação, construídas com uma simbologia gráfica composta por figuras, letras ou palavras escritas, e podem associar vocalização, que é a sonorização da palavra ou frase correspondente, com o uso de aparelhos eletrônicos. A Figura 1 apresenta o usuário utilizando uma imagem na prancha de comunicação (assistido).

Figura 1 - Exemplo de utilização de pranchas de comunicação e vocalizadores

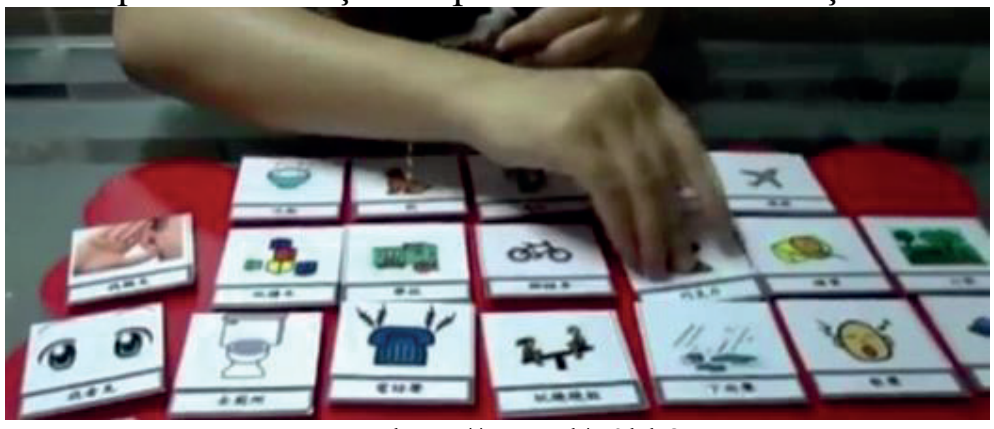

Fonte: http://goo.gl/50bk2U

Um sistema de comunicação gráfico, ou pictográfico, é uma coleção de imagens gráficas que apresentam características comuns entre si e foram criados para responder a diferentes exigências ou necessidades dos usuários (BERSCH, 2008). Para os autistas, esses sistemas são amplamente utilizados com objetivo de viabilizar a comunicação direta, estimular a comunicação oral e reduzir a frequência de comportamentos indesejados, compondo rotinas visuais (NUNES; NUNES SOBRINHO, 2010).

Dentre as técnicas de intervenção mais citadas, segundo análise de Rodrigues e Silva (2013) acerca dos artigos da Revista Brasileira de Educação Especial acerca da Comunicação Suplementar e Alternativa, cita-se o PCS (Picture Communication Symbols), o PECS (Picture Exchange Communication System), e sistemas que utilizavam mais de um método de 
comunicação, adaptados ao aprendizado individual. Cada um utiliza um grupo de figuras próprio que dá um significado a conceitos reais. Conforme a hierarquia de símbolos proposta por Mirenda e Locke, em 1989, os sistemas de comunicação apresentam graus de iconicidade, demonstrando que quanto mais icônico for um símbolo, melhor ele representa, ou ajuda a lembrar, o objeto real (NUNES, 2013).

Para Almeida, Piza e Lamônica (2005) o Sistema PCS possui “símbolos com desenhos simples e de fácil reconhecimento de seu significado, sendo divididos em categorias denominadas: social, pessoas, verbos, descritivos, substantivos e miscelânea".

Já as PECS geralmente utilizam as figuras do PCS, porém usa uma metodologia de aplicação dividida em fases: 1) Fazer pedidos por meio da troca de figuras pelos itens desejados; 2) Ir até a tábua de comunicação, apanhar uma figura, ir a um adulto e entregá-la em sua mão; 3) Discriminar entre as figuras; 4) Solicitar itens utilizando várias palavras em frases simples, fixadas na tábua de comunicação; 5) Responder à pergunta $\mathrm{O}$ que você quer; 6) Emitir comentários espontâneos (MIZAEL; AIELLO, 2013).

Outro conjunto de figuras bastante utilizado é encontrado no ARASAAC ${ }^{3}$ que consiste num repositório com várias figuras para utilização sob licença Creative Commons, que permite o uso para fins que não visam lucro e devem citar a fonte e o autor. O ARASAAC é mantido pelo governo de Aragon, uma comunidade independente da Espanha (FOSCARINI; PASSERINO, 2013).

Rodrigues e Silva (2013), Ferreira (2012), Almeida, Piza e Lamônica (2005) explicam que os estudos no uso de figuras para auxiliar a comunicação com autistas demonstram resultados positivos no desenvolvimento dos participantes, porém não é possível definir uma técnica ou conjunto de figuras específico para ajudar a todos os casos, em virtude das peculiaridades individuais existentes no Transtorno do Espectro do Autismo.

\section{TRAJETÓRIA METOLOGICA}

O Papagaio Amigo (SILVA, 2017) foi idealizado a partir dos estudos de ferramentas e sistemas existentes no mercado em conjunto com LEI em parceria com o Laboratório de Sistemas Digitais (LSD) ${ }^{4}$, referentes as diferentes necessidades de comunicação do autista.

Foi definido como objetivo geral da pesquisa: implementar um aplicativo baseado nos conceitos da Tecnologia Assistiva e na Comunicação Alternativa e Aumentativa, para a comunicação de autistas utilizando parte das figuras do ARASAAC e do cotidiano do usuário. Como objetivos específicos tem-se: Desenvolver o aplicativo Papagaio Amigo; validar considerando critérios de usabilidade, acessibilidade e robustez e avaliar potencialidades e limitações na perspectiva dos profissionais e/ou responsáveis que atuam ou atuaram com autistas.

Tendo como pergunta norteadora: "Quais as potencialidades e limitações do Papagaio Amigo para a comunicação considerando crianças autistas?", buscou-se na implementação as ações para desenvolver, aplicar, validar e avaliar a TA, optando metodologicamente por duas vertentes: uma voltada para a implementação/desenvolvimento do aplicativo, considerando o ciclo de desenvolvimento de software, e a outra, de cunho qualitativo descritivo, envolvendo a avaliação da aplicação na perspectiva dos orientadores (responsáveis, profissionais da área da saúde e educação).

\footnotetext{
${ }^{3}$ Portal Aragonês de Comunicação Alternativa e Ampliada, disponível em http://arasaac.org/

${ }^{4}$ LSD - Laboratório de Sistemas Digitais do Curso de Ciência da Computação da Ulbra/Gravataí.
} 
Na visão da Engenharia de Software, implementar está relacionado ao processo, desde a definição dos requisitos para o desenvolvimento até a sua validação, constituindo o ciclo de vida: Análise dos Requisitos; Projeto do Sistema e Programa; Codificação; Teste de Integração e Unidade, do sistema, de aceitação; Operação e Manutenção (PFLEEGER, 2004).

Após a implementação/desenvolvimento do aplicativo, optou-se por validar/avaliar, tendo como sujeitos responsáveis, professores, monitores, profissionais da saúde que auxiliam na comunidade de crianças autistas. Para tanto foram elaboradas perguntas por meio de um questionário online, por acreditarmos que dessa forma seria possível obter dados quanto de diferentes pessoas e localidades. Mattar (1999) relata que é pertinente ao objetivo das pesquisas exploratórias a busca por aprofundar o conhecimento quando a compreensão do fenômeno a ser estudado. Dessa forma, a ponderação sobre os resultados foi realizada por meio da análise descritiva interpretativa, na qual o pesquisador propõe inferências, embasando suas análises ou novas descobertas, dando significado à interpretação (ROSENTHAL, 2014).

\section{CONSTRUÇÃO E IMPLEMENTAÇÃO DO PAPAGAIO AMIGO}

O Papagaio Amigo, possui um logo colorido, com traços criados a partir de um Origami ${ }^{5}$, e o nome faz alusão às características de um papagaio doméstico que repete as mensagens das pessoas. $\mathrm{O}$ aplicativo propõe um conjunto de figuras para auxiliar usuários autistas, para sua comunicação com um interlocutor. O fluxo básico para acesso, escolha e transmissão envolve: 1. O usuário escolhe uma categoria (que contém a figura desejada para comunicação), tocando-a na tela;

2. Na categoria o usuário escolhe a figura desejada para comunicar, tocando-a na tela;

3. O aplicativo transmite em áudio o significado da figura tocada;

4. O aplicativo armazena o textual da figura escolhida em local reservado, e aguarda uma nova escolha;

5. A qualquer momento é possível transmitir o áudio completo formado pelo textual das figuras já escolhidas, com um botão junto ao local reservado.

Figura 2 - Ilustração da hierarquia de figuras da categoria inicial Aprendizagem

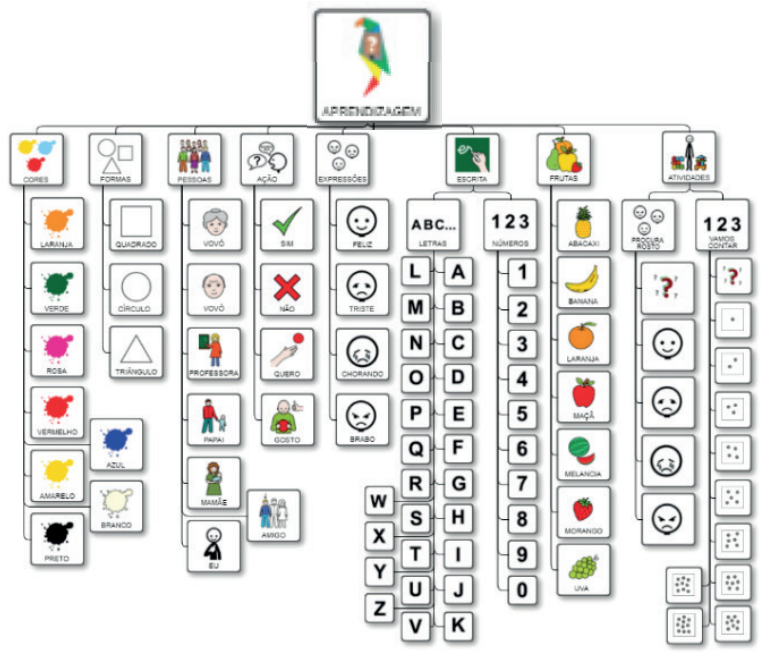

Fonte: Silva, 2017, p. 32.

As categorias apresentadas inicialmente com o ARASAAC (Figura 2) podem ser modificadas e/ou redefinidas pelo Orientador (pessoa que irá acompanhar o autista no uso do

\footnotetext{
${ }^{5}$ Representações em formatos de animal ou objeto feito em papel usando dobras.
} 
aplicativo), preferencialmente na primeira utilização da ferramenta. Este organiza e define quais serão as existentes, seus respectivos nomes, assim como as figuras pertencentes a cada conjunto. Estas escolhas permitem uma flexibilidade em personalizar conforme as reais necessidades do usuário.

Para uma melhor experiência de acesso do usuário no aplicativo, o orientador define o tamanho ocupado pelas categorias ou figuras, que representam botões na tela e aguardam o toque do usuário. Desta forma o tamanho será adequado ao grau de visão ou necessidade do utilizador, sendo representadas as figuras em linhas e colunas, adaptando a quantidade destas de acordo com o tamanho especificado e da tela do dispositivo móvel. Caso não seja possível apresentar todas as figuras da categoria de uma única vez, a tela apresenta navegação na vertical, deslizando o dedo na tela do centro para as extremidades, superior ou inferior.

Figura 3 - Tela do aplicativo em 4 e 7 polegadas
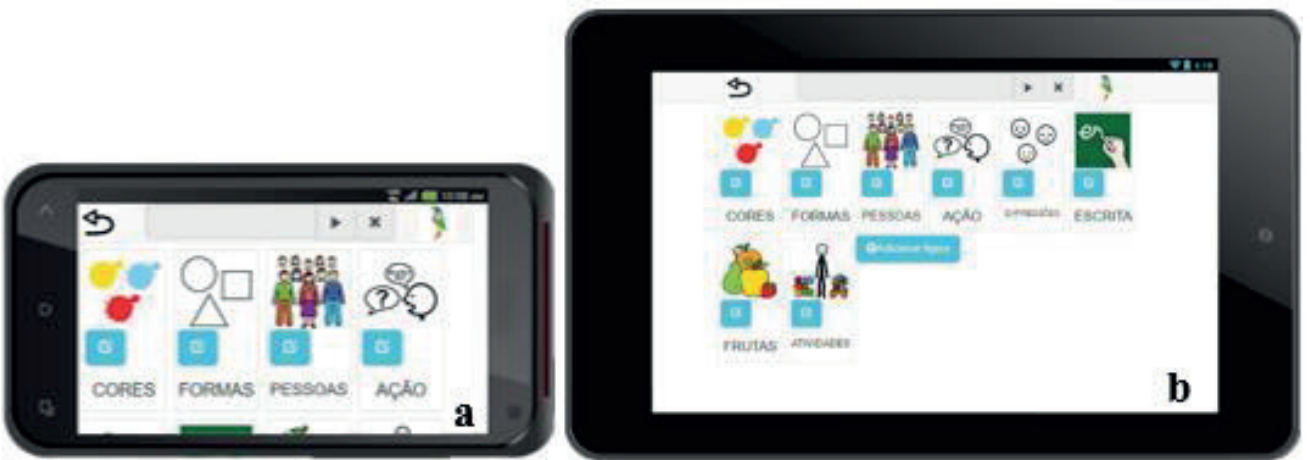

Fonte: Silva, 2017, p. 32.

A Figura 3 apresentam prints da tela principal do aplicativo. Na Figura 4a o layout é adaptado em um smartphone com tamanho de tela em 4 polegadas, e na Figura $4 \mathrm{~b}$ o mesmo é apresentado em um tablet com tamanho de tela de 7 polegadas.

As áreas superiores das Figuras 3a e 3b apresentam um local reservado da navegação, citado no fluxo de uso descrito anteriormente. Esta área é fixa no topo da aplicação durante todo seu uso, onde constam os seguintes elementos (da esquerda para direita):

- Seta de retorno: O ícone para retornar ao nível superior, saindo da categoria atual e retornando ao nível que esta categoria pertence;

- Um campo de texto para armazenar a construção da mensagem, composta pela sequência de figuras escolhidas pelo usuário. Este espaço é ligado a dois botões do lado direito, sendo o primeiro responsável por reproduzir sonoramente a sequência de palavras e o segundo para apagar a última palavra;

- Uma figura que identifica a categoria em navegação atual na área inferior. A primeira categoria no maior nível do aplicativo tem como imagem o logo Papagaio Amigo.

Durante a definição das figuras que serão utilizadas, o Orientador pode alterar as mesmas por imagens ou fotos, personalizando a identificação das mensagens pelo usuário. Por exemplo, uma figura do ARASAAC que representa um cachorro pode ser substituída por uma foto do próprio cachorro de estimação do usuário ou de uma pessoa próxima ou ainda de um personagem conhecido pelo autista.

A Figura 4 apresenta o storyboard de acesso para a edição de figuras, utilizando como exemplo a personagem mamãe, além de detalhes na identificação da tela como a categoria atual apresentada no topo. Na edição de uma figura é possível escolher, por meio de botões, as seguintes opções: 
- Nova Foto: permite a troca de imagem de outro arquivo já disponível no dispositivo, ou com de uma nova foto utilizando os recursos de câmera;

- Novo Áudio: permite a troca de áudio com os recursos do gravador de som;

- Descrição: permite alterar o textual que dá significado à figura;

- Categorizar: permite alterar o tipo da figura para "categoria", ou seja, ao tocá-la não reproduzirá mais o áudio e abrirá uma nova subcategoria, inicialmente vazia;

- Mover: permite mover a figura para o início ou final da categoria atual, ajustando o valor da propriedade "ordem". Também é possível retirar a figura da categoria atual e inseri-la em outra categoria já existente no aplicativo;

- Remover: permite excluir, mediante confirmação, a figura do aplicativo.

Figura 4 - Storyboard com sequência de acesso à tela "Configurar figura"

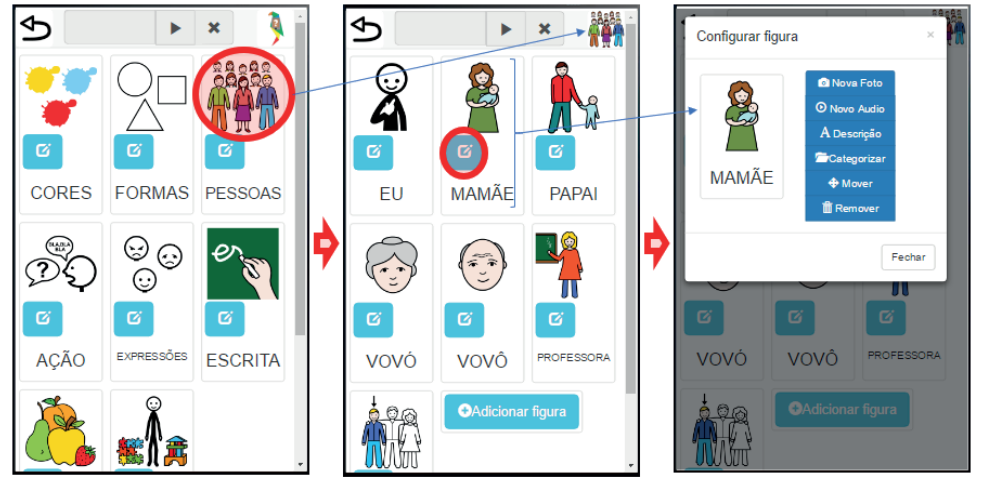

Fonte: Silva, 2017, p. 35.

Para o desenvolvimento foi utilizada a ferramenta Intel XDK, com linguagem HTML5, CSS e JavaScript, posteriormente convertido em App Nativo. Segundo a Intel ${ }^{6}$ a ferramenta XDK oferece um fluxo de trabalho simplificado para auxiliar os desenvolvedores a facilmente projetar, depurar, construir e distribuir aplicativos híbridos e de web em HTML5, em múltiplas lojas de aplicativos e para dispositivos em diversos formatos.

A conversão da aplicação acontece com a ferramenta online Phonegap Builder, que faz a comunicação entre plugins, criados em JavaScript, com um renderizador de páginas Web oferecido pelo Sistema Operacional. Esse renderizador é a ponte de comunicação para recursos do hardware, como câmera e microfone que estão apresentados nas características do aplicativo desenvolvido.

\section{VALIDAÇÃO E DISCUSSÕES DOS RESULTADOS}

A validação foi executada em duas etapas: primeiramente realizada por profissionais de diferentes áreas do conhecimento, sendo a grande maioria com experiência em comunicação. De um total de 31 avaliadores, 15 atuam na área da educação e saúde; 10 são pais/responsáveis e 6 são amigos ou colegas de autistas. A segunda etapa foi com uma criança autista de 6 anos, ingressante no ensino fundamental. O questionário online foi confeccionado considerando os aspectos de robustez, acessibilidade e conhecimento sobre Comunicação Alternativa.

Vinte e dois dos participantes disseram que já obtiveram algum contato com materiais sobre Comunicação Alternativa, sendo que apenas dois deles apontaram o objetivo do uso para o aprendizado, e dezessete para comunicação, que corresponde a $54 \%$ de todas as respostas. Identificou-se também que, aproximadamente, metade das pessoas responderam que já utilizaram algum tipo de figura ou material manual para comunicar-se e apenas $22 \%$ fizeram uso de aplicativos ou vocalizadores.

\footnotetext{
${ }^{6}$ Empresa de tecnologia. Descrição disponível em https://software.intel.com/pt-br/intel-xdk
} 
Foi unânime a afirmativa, quando questionados se acreditavam que o uso de tecnologias poderia facilitar o processo de comunicação. O Participante 14 relatou: "Sim, muito. A tecnologia exerce um fascínio em pessoas das mais variadas idades e, se bem utilizada, agrega no processo de estimulação e aumento da comunicação". O que nos trouxe uma certeza de continuar desenvolvendo tecnologias no grupo de pesquisa.

Quando perguntados se o aplicativo Papagaio Amigo é uma ferramenta que contribui para o âmbito da comunicação alternativa, as respostas foram positivas. O Participante 4 expressa que "esse tipo de recurso vem para contribuir e acrescentar ao trabalho pedagógico. É uma importante ferramenta que pode facilitar o processo de ensino e de aprendizagem através da comunicação correta!".

Por ser um aplicativo que se adapta aos diversos tamanhos de tela, devido ao design responsivo $^{7}$, a validação na questão de acessibilidade foram consideradas dentro do padrão, tendo a aceitação definida como ótima, bem como na robustez, pois em nenhum momento foi relatado problemas durante o uso.

Quanto a clareza das informações apresentadas, muitos participantes entraram em contato com o desenvolvedor por e-mail (disponibilizado no questionário) questionando o funcionamento da ferramenta, em especial na tela inicial que solicitava cadastrar Orientador e Usuário. Então um tutorial foi acrescentado explicando que o Orientador seria a pessoa que acompanha o autista (usuário). Dentro das questões sobre a clareza das informações foram solicitadas a verificação de itens como audiovisual acessível, claro e coerente; navegação fácil de localizar; imagens claras e definidas; áudio claro e definido e interface agradável e legível. Em todos esses quesitos os respondentes afirmaram que estavam de boa qualidade.

Quando perguntados sobre os elementos audiovisuais apresentados se facilitavam a memorização do conteúdo ou tornavam a comunicação mais fácil, obtivemos respostas muito positivas, como a do Participante 13 "mesmo que a resposta do usuário não seja automática, minha experiência vem mostrando que os recursos audiovisuais ajudam a memorização e aplicação do que foi aprendido em momento oportuno".

Ainda o Participante 16 ressaltou que "gostou da possibilidade de criar novos itens no aplicativo", referindo-se à possibilidade de inserir novas categorias e figuras. Já o Participante 30 descreveu o aplicativo como "uma ferramenta que permite através de imagens e sons a facilidade de entendimento e memorização por meio de símbolos, números e palavras".

Finalizando as questões todos os participantes afirmaram que indicariam a aplicação Papagaio Amigo para utilizar com pessoas diagnosticadas com TEA.

Uma questão aberta foi disponibilizada solicitando críticas e sugestões. Entre as sugestões recebidas encontramos a criação de um manual de instruções para auxiliar o orientador inexperiente a utilizar todos os recursos do aplicativo, o participante 20 sugere "Pode ter um manual simples e básico disponível na internet para saber usar todas as possibilidades do App". Também sugeriram o aumento na quantidade de categorias, pela internet ou em novas versões, tornando o app colaborativo.

Além do questionário aplicado, o Participante 31 compartilhou sua emoção ao descrever o uso do aplicativo pela sua filha, atualmente com seis anos de idade e diagnosticada com TEA desde os dois anos e meio. Ele explica que, como ela já possui experiência na manipulação de celulares assistindo vídeos e jogos, a usuária aprendeu rapidamente as funções básicas da ferramenta. Complementando cita o seguinte exemplo para ilustrar as habilidades de sua filha:

\footnotetext{
${ }^{7}$ Design Responsivo: é uma abordagem ao design da web que torna as páginas da web renderizadas em uma variedade de dispositivos e tamanhos de janelas ou tela, ou seja, se adaptam ao tamanho do dispositivo.
} 
"Minha esposa pegou o Smartphone e tocou nas figuras para formar a frase 'Eu não gosto vermelho', então minha filha autista apagou parte das palavras no campo de reprodução e deixou sua resposta: 'Eu gosto"'. Quanto às atividades, a usuária ouviu as instruções e facilmente detectou expressões faciais ou quantidades pequenas como mostra a Figura 6.

Figura 5 - Usuária autista, filha do Participante 31, usando a aplicação.
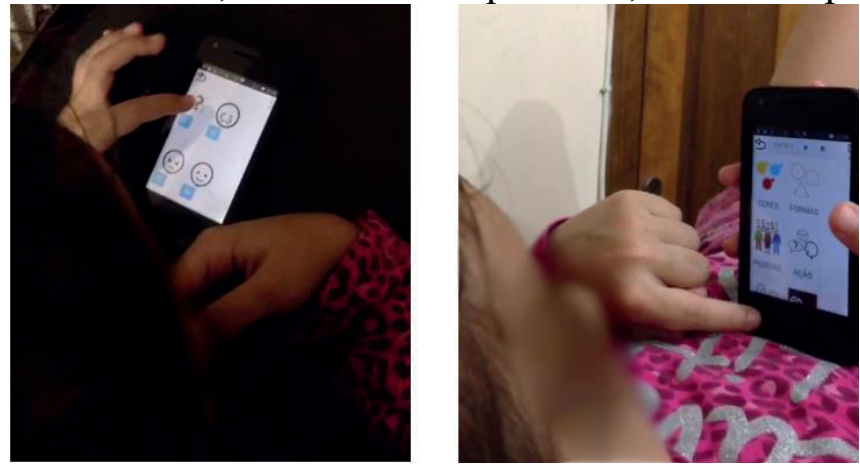

Fonte: Silva, 2017, p. 47.

A continuidade desse aplicativo foi construída a partir das sugestões coletadas, com o intuito de expandir a criação de categorias de forma colaborativa, compartilhando figuras e áudios em uma página da web, sendo disponibilizado em https://play.google.com/store/apps/details?id=tcc.amigo.papagaio\&hl=pt.

\section{CONSIDERAÇÕES FINAIS}

O TEA, conforme as principais organizações psiquiátricas do mundo, é considerado um TGD que afeta comportamentos sociais do indivíduo desde os primeiros anos de vida, incluindo a comunicação. Diante destas características, buscaram-se métodos de intervenção mediadas pela TA, que oferece recursos e serviços para auxiliar e diminuir os efeitos da deficiência, promovendo a inclusão.

Dentre as categorias da TA, a área da Comunicação Alternativa oferece figuras e símbolos que estimulam e suplementam a fala, utilizados principalmente com as pranchas de comunicação e vocalizadores, nos quais o presente trabalho se inspirou para desenvolver o aplicativo, pesquisando as atuais características dos dispositivos móveis e os Sistemas Operacionais que gerenciam o hardware, onde detectou diferentes formas de desenvolvimento de aplicativos, diante da incompatibilidade das interfaces no mercado.

Para o processo de análise inicial do aplicativo Papagaio Amigo, o trabalho teve o cuidado de identificar as ferramentas que já existem no mercado, entre aplicativos e aparelhos eletrônicos, e o que poderia ser desenvolvido para ajudar ainda mais os usuários. Assim, foram apresentadas características importantes para construção de um aplicativo estável, utilizado como auxiliar na vocalização, podendo apoiar o processo de inclusão do usuário.

\section{REFERÊNCIAS BIBLIOGRÁFICAS}

ALMEIDA, M. A; PIZA, M. H. M.; LAMONICA, D. A. C. Adaptações do sistema de comunicação por troca de figuras no contexto escolar. Pró-Fono R. Atual. Cient., Barueri: 2005. v. 17, n. 2. Disponível em: $<$ http://www.scielo.br/scielo.php?script=sci_arttext\&pid=S0104-6872005000200012\& lng=en\&nrm=iso $>$. Acesso em: 02 abr. 2015.

BERSCH, R. Introdução à tecnologia assistiva. Porto Alegre: CEDI - Centro Especializado em Desenvolvimento Infantil, 2008. Disponível em: <http://proeja.com/portal/images/semana-quimica/201110-19/tec-assistiva.pdf>. Acesso em: 05 mar. 2015.

FERREIRA, D. M. Métodos clínicos fonoaudiológicos utilizados no atendimento de pacientes com transtorno global do desenvolvimento: Revisão sistemática de literatura. São Paulo: PUC-SP, 2012. 
Disponível em: <http://www.sapientia.pucsp.br/tde_arquivos/16/TDE-2013-03-20T08:40:06Z13463/Publico/Danielle\%20Miranda\%20Ferreira.pdf $>$ Acesso em: 01 abr. 2015.

FOSCARINI, A. C; PASSERINO, L. M. Escalando possibilidades de comunicação e interação em crianças com autismo não oralizadas. In: V congresso brasileiro de Comunicação Alternativa. Isaac Brasil: 2013. Disponível em: <http://www.ufrgs.br/teias/isaac/VCBCAA/pdf/115834_1.pdf> Acesso em: 30 abr 2015.

GARCÍA, J. C. D; GALVÃO FILHO, T. A. Pesquisa Nacional de Tecnologia Assistiva. São Paulo: ITS BRASIL/MCTI-SECIS, 2012.

MANUAL DIAGNÓSTICO E ESTATÍSTICO DE TRANSTORNOS MENTAIS: DSM-5. [American Psychiatric Association. tradução: Maria Inês Corrêa Nascimento ... et al.]; revisão técnica: Aristides Volpato Cordioli ... et al.]. $5^{\text {a }}$ ed. Porto Alegre: Artmed, 2014.

MATTAR, F. N. Pesquisa de marketing: metodologia e planejamento. 5.ed. São Paulo: Atlas, 1999.

MIZAEL, T. M; AIELLO, A. L. R. Revisão de estudos sobre o Picture Exchange Communication System (PECS) para o ensino de linguagem a indivíduos com autismo e outras dificuldades de fala. In: Rev. bras. educ. espec., Marília: 2013. v.19, n.4, p. 623-636. Disponível em:

$<$ http://www.scielo.br/pdf/rbee/v19n4/v19n4a11.pdf $>$. Acesso em: 01 abr. 2015.

NUNES, D. Comunicação alternativa e ampliada para pessoas com Autismo. In: Schmidt, Carlo. (org). Autismo, educação e transdisciplinaridade. Campinas: Papirus, 2013. cap. 8, p.145-164.

NUNES, D. R. de P; NUNES SOBRINHO, F. de P. Comunicação alternativa e ampliada para educandos com autismo: considerações metodológicas. In: Rev. bras. educ. espec., Marília: 2010. v.16, n.2.

Disponível em: $<$ http://www.scielo.br/scielo.php?pid=S1413-

65382010000200010\&script=sci_arttext\&tlng=es $>$. Acesso em: 31 mar. 2015.

OMS. CID-10 - Classificação estatística internacional de doenças e problemas relacionados à saúde. São Paulo: Centro Brasileiro de Classificação de Doenças. 2008. Disponível em:

$<$ http://www.datasus.gov.br/cid10/V2008/WebHelp/ f80_f89.htm\#F84>. Acesso em: 17 mar. 2015.

PASSERINO, L. M; BEZ, M. R.; AVILA, B. G. Sistema de comunicação alternativa para o letramento de pessoas com autismo. In: Congreso Internacional Comunidad Inclusiva - FIDA 2010 SICA, 2010, Uruguai. Anais Comunidad Inclusiva - FIDA 2010 SICA, 2010. v. 1. p. 1-10.

PASSERINO, L.M; AVILA, B. G; BEZ, M. R. SCALA: um sistema de comunicação alternativa para o letramento de pessoas com autismo. RENOTE - Revista Novas Tecnologias na Educação. V. 8 No 2, julho, 2010.

PELOSI, M. B. Tecnologias em comunicação alternativa sob o enfoque da terapia ocupacional. In: D.

Deliberato, M. J. Gonçalves, E.C. Macedo (Orgs.). Comunicação Alternativa: teoria, prática, tecnologias e pesquisa. São Paulo: Memnon Edições Científicas, 2009.

PFLEEGER, S. L. Engenharia de software: teoria e prática. 2. ed. São Paulo: Prentice Hall, 2004.

RODRIGUES, V; SILVA, G. P. Análise dos artigos da Revista Brasileira de Educação Especial acerca da comunicação suplementar e alternativa. In: $\mathrm{V}$ congresso brasileiro de Comunicação Alternativa. Isaac Brasil: 2013. Disponível em: <http://www.ufrgs.br/teias/isaac/VCBCAA/pdf/115805_1.pdf $>$ Acesso em: 01 abr 2015.

ROSENTHAL, G. Pesquisa social interpretativa: uma introdução. 5. ed. Porto Alegre: EDIPUCRS, 2014.

SILVA, A.B.B; GAIATO, M.B; REVELES, L.T. Mundo singular: entenda o autismo. Rio de Janeiro: Objetiva, 2012.

SILVA. J. F. Aplicativo vocalizador com atividades lúdicas para autistas. Monografia de Conclusão de Curso de Ciência da Computação. Ulbra - Universidade Luterana do Brasil - Campus Gravataí. Gravataí: 2017. 